\title{
Drug utilisation study in medicine outpatient department at Ashwini Rural Medical College, Kumbhari, Solapur, India
}

\author{
Pramod P. Bhalerao, Chandrakant S. Waghmare*
}

Department of Pharmacology, Ashwini Rural Medical College and Research Centre, Kumbhari, Solapur, Maharashtra, India

Received: 14 June 2019

Revised: 30 June 2019

Accepted: 06 July 2019

*Correspondence to:

Dr. Chandrakant S. Waghmare,

Email: drckant@gmail.com

Copyright: (C) the author(s), publisher and licensee Medip Academy. This is an openaccess article distributed under the terms of the Creative Commons Attribution NonCommercial License, which permits unrestricted noncommercial use, distribution, and reproduction in any medium, provided the original work is properly cited.

\begin{abstract}
Background: Drug utilization studies are used to analyze different aspects of the use of drugs and to implement methods of improving therapeutic quality. This study was conducted to study drug prescription pattern in Medicine Outpatient Department (OPD) in Ashwini Rural Medical College, Kumbhari.

Methods: Six hundred prescriptions were screened \& analyzed as per the study parameters at Medicine OPD of Ashwini Rural Medical College, Kumbhari. Study parameters like demographic profile of the patient like age, sex and diagnosis were recorded. Doctor details and patient details like age, sex and address were analyzed. Also, groups of drugs commonly prescribed, number of drugs per patient, drug profile and drawbacks of prescription if any were recorded and analyzed.

Results: Most common group of drugs prescribed by physicians were Analgesics $(21.84 \%)$, followed by Drugs for Peptic ulcer $(17.92 \%)$ and Multivitamins/multimineral (14.70\%). The average number of drugs prescribed per patient was 2.38. The incidence of Polypharmacy was common occurrence and some prescriptions had small drawbacks like absence of diagnosis, absence of doctor's signature, etc.

Conclusions: Authors conclude that most of the prescriptions which were analyzed at Ashwini Rural Medical College Hospital, Kumbhari, were according to the standard norms of WHO prescriptions and also most of the drugs prescribed were from the list of essential drug list. But still there is scope for improvement in prescription pattern.
\end{abstract}

Keywords: Drug utilization, Outpatient department, Prescription analysis

\section{INTRODUCTION}

A prescription-based survey is considered to be one of the most effective methods to assess and evaluate the prescribing attitude of physicians and prescription based drug utilization studies are more meaningful to observe the prescribing attitude of physicians with the aim to provide drugs rationally.

The results of these types of studies, which were carried out at different health care centers are used to evaluate and analyze the medical, social and economic outcomes of the drug therapy. ${ }^{1}$
The World Health Organization (WHO) addressed drug utilization as "the marketing, distribution, prescription and use of drugs in a society, considering its consequences, medical, social, and economic". ${ }^{2}$ Drug utilization studies can provide very important information, at a reasonable price, on the costs and effects either harmful or beneficial of drugs. Such studies provide much useful information including indirect data on morbidity, the pharmaceutical component of the treatment cost of an illness, therapeutic compliance, the incidence of adverse drug reactions and the effectiveness of drug consumption. ${ }^{3}$ Drug utilization data may be used to produce crude estimates of disease prevalence also. ${ }^{4}$ 
Although, a number of studies have been undertaken to study the drug prescribing pattern of different medical and dental colleges, but no study was conducted to evaluate drug utilization pattern of outpatient department of Medicine in Ashwini Medical College, Kumbhari. ${ }^{4-9}$

\section{METHODS}

Permission from the Human Ethics Committee of the institute was taken to carry out this study. It is a prospective, randomized observational study which was carried out over a period of six months.

Prescriptions of the patients attending the Medicine outpatient department at ARMCH, Kumbhari were selected. Prescriptions were scanned by mobile and all scanned prescriptions were examined with reference to study parameters. Accordingly, a sample of six hundred $(n=600)$ prescriptions of either sex were randomly selected for prescription pattern analysis. Collected prescriptions were analyzed based on the objective of the study. The age and sex of the patients, groups of drugs commonly prescribed, number of drugs per patient, drug profile and drawbacks of prescription if any were recorded and analyzed.

Sample size was 600 prescriptions.

Inclusion criteria was all patients visiting Medicine outpatient department of ARMCH, Kumbhari. Study period was 6 months (July 2018- Dec 2018).

\section{Statistical analysis}

Descriptive statistics such as frequency and percentage were used to present the data. Microsoft Excel was used to prepare tables.

\section{RESULTS}

Data of patients $(n=600)$ was analyzed according to the study parameters. Total number of drugs prescribed in these patients were 1428. Therefore, average number of drugs per patient was 2.38. Most common drugs prescribed were Analgesics (21.84\%), Drugs for peptic ulcer $(17.92 \%)$ and Multivitamin/Multimineral (14.70\%). Corticosteroids were less frequently prescribed $(0.98 \%)$ (Table 1).

Hierarchy of drugs in prescriptions containing 2 or more than 2 drugs should be as follows:

1. Injection

2. Oral preparations in this order

- Capsules

- Tablets

- Liquids

3. Topical preparation

Hierarchy of drugs in prescriptions containing 2 or more than 2 drugs was maintained in 399/438 prescriptions (91.09\%). Only $4.20 \%$ of the drugs were prescribed by generic name (Table 4).

Table 1: Common categories of drugs prescribed to Medicine OPD.

\begin{tabular}{|lll|}
\hline Category of drugs & Total out of $\mathbf{1 4 2 8}$ drugs prescribed & Percentage \\
\hline Antimicrobials & 60 & $4.20 \%$ \\
\hline Antidiabetics & 85 & $5.95 \%$ \\
\hline Antihypertensives & 155 & $10.85 \%$ \\
\hline Antihistaminics & 87 & $6.09 \%$ \\
\hline Analgesics & 312 & $21.84 \%$ \\
\hline Multivitamin/Multimineral & 210 & $14.70 \%$ \\
\hline Corticosteroids & 14 & $0.98 \%$ \\
\hline Drugs for Peptic ulcer & 256 & $17.92 \%$ \\
\hline Drugs for Anxiety/Insomnia & 57 & $3.99 \%$ \\
\hline Miscellaneous & 192 & $13.44 \%$ \\
\hline
\end{tabular}

The incidence of Polypharmacy was also common occurrence. Number of prescriptions containing 3 drugs (28.5\%) and number of prescriptions containing 2 drugs $(28.5 \%)$ were the commonest occurrence (Table 2). Various problems were also encountered in these prescriptions. Doctors sign was absent in $15 \%$ of the prescriptions. Patient age was not written in $90 \%$ of the prescriptions. Patient sex was not written in $92.33 \%$ of the prescriptions. Patients address was not written in $96.66 \%$ of the prescriptions.

Diagnosis was not written in $96 \%$ of the prescriptions. Duration of treatment was not written in $5 \%$ of the prescriptions (Table 5). 
Table 2: Number of drugs prescribed per prescription.

\begin{tabular}{|lll|}
\hline $\begin{array}{l}\text { Prescription containing } \\
\text { Number of drugs }\end{array}$ & $\begin{array}{l}\text { Total out of } \mathbf{6 0 0} \\
\text { prescriptions }\end{array}$ & $\%$ \\
\hline 1 drug & 162 & $27 \%$ \\
\hline 2 drugs & 171 & $28.5 \%$ \\
\hline 3 drugs & 171 & $28.5 \%$ \\
\hline 4 drugs & 72 & $12 \%$ \\
\hline 5 drugs & 21 & $3.5 \%$ \\
\hline 6 drugs & 3 & $0.5 \%$ \\
\hline
\end{tabular}

Table 3: Dosage forms.

\begin{tabular}{|lll|}
\hline $\begin{array}{l}\text { Dosage } \\
\text { forms }\end{array}$ & $\begin{array}{l}\text { Total out of } \mathbf{1 4 2 8} \text { drugs } \\
\text { prescribed }\end{array}$ & $\%$ \\
\hline Oral & 1298 & $90.90 \%$ \\
\hline Topical & 115 & $8.05 \%$ \\
\hline Injectable & 15 & $1.05 \%$ \\
\hline
\end{tabular}

Table 4: Drug prescription by generic and brand names.

\begin{tabular}{|lll|}
\hline Drug Prescription & $\begin{array}{l}\text { Total out of } \\
\mathbf{1 4 2 8} \text { drugs }\end{array}$ & $\%$ \\
\hline $\begin{array}{l}\text { Drugs prescribed by } \\
\text { generic name }\end{array}$ & 60 & $4.20 \%$ \\
\hline $\begin{array}{l}\text { Drugs prescribed by } \\
\text { brand name }\end{array}$ & 1368 & $95.80 \%$ \\
\hline
\end{tabular}

Table 5: Prescription related parameters.

\begin{tabular}{|lll|}
\hline $\begin{array}{l}\text { Prescription related } \\
\text { parameters }\end{array}$ & $\begin{array}{l}\text { Total out of } \\
\mathbf{6 0 0} \\
\text { prescriptions }\end{array}$ & $\%$ \\
\hline Doctors name not written & Zero & $0 \%$ \\
\hline Doctors sign absent & 90 & $15 \%$ \\
\hline $\begin{array}{l}\text { Doctor Registration No. } \\
\text { absent }\end{array}$ & Zero & $0 \%$ \\
\hline Patient name not written & Zero & $0 \%$ \\
\hline Patient age not written & 540 & $90 \%$ \\
\hline Patient sex not written & 554 & $92.33 \%$ \\
\hline Patient address not written & 580 & $96.66 \%$ \\
\hline Diagnosis not written & 576 & $96 \%$ \\
\hline Date not written & Zero & $0 \%$ \\
\hline $\begin{array}{l}\text { Duration of treatment not } \\
\text { written }\end{array}$ & 30 & $5 \%$ \\
\hline
\end{tabular}

Dose of the drug was not written in $780 / 1428$ of the drugs $(54.62 \%)$. Drugs name in capitals was written in only 90/1428 drugs (6.3\%). Drugs prescribed from National List of Essential Medicines (NLEM) were $60.22 \%$ which increases rationality of the prescription.

\section{DISCUSSION}

Drug utilization studies are used to analyze different aspects of the use of drugs and to implement ways of improving therapeutic quality, keeping in mind the fact that health resources are very limited. The present study was conducted to study drug utilization pattern in Medicine outpatient department of Ashwini Rural Medical College, Kumbhari, Maharashtra. The most common groups of drugs were Analgesics, drugs for peptic ulcer and multivitamin/Multimineral.

The average no. of drugs prescribed by injection was very low (1.05\%). Most of the drugs were given by oral route, which is the convenient way for drug administration, and it is also cost effective for the patients.

Average number of drugs per encounter in the present study was found to be 2.38. Polypharmacy increases the cost of therapy unless the prescribed drugs are genuinely necessary. Also, it decreases compliance of the patient so the drugs should be used judiciously.

Percentage of drug prescribed by generic name, in present study was $4.20 \%$. Prescribing medicines by generic name avoid the confusion and makes therapy rational and cheaper. Moreover, in the teaching institutions world over, in textbooks, in scientific journals and in the research publications, medicines are always mentioned by generic names. Despite this, most doctors prescribe the medicines by their brand names. The reason for this could be (1) tradition (2) aggressive medicine promotion (3) availability of multi-ingredient fixed dose drug combination. ${ }^{10}$ Encouraging prescriptions by generic names is always recommended by various national and international bodies to promote rational use of drugs. ${ }^{11}$

The drugs if prescribed by generic name also gives the advantage to the pharmacist to dispense the cheaper drugs to the patients, this helps to reduce the economic burden on patients. Also, this practice will certainly help to check the luring practices if offered by some of the pharmaceutical companies to the practitioners for promoting their costlier brands. But implementation of this practice of prescribing by generic names is not always satisfactory and requires motivation of prescribers and strong regulatory interventions. ${ }^{11}$

WHO has defined "Essential medicines are those that satisfy the priority health care needs of the majority of population. ${ }^{6}$ In the present study, results showed that the percentage of drugs prescribed from essential drug list was $(60.22 \%)$, analysis was done with reference to Tripathi KD. ${ }^{12}$

Essential drugs should be preferred during prescribing. Prescription from the Essential drug list gives maximum benefit from limited resource, promotes rational use of drugs, assists the development of standard use of standard treatment protocol and rational prescribing policies and also increases economic advantages like lowering the cost of therapy. ${ }^{6}$ 
Doctors signature was absent in $15 \%$ of the prescriptions. Doctor's signature is important for medicolegal aspects. Patient age was not written in $(90 \%)$ prescriptions. Patient sex was not written in $(92.33 \%)$ prescriptions. Patients address was not written in $(96.66 \%)$ prescriptions.

Patient information is required for medicolegal purposes. Diagnosis was not written in $(96 \%)$ of the prescriptions. Diagnosis is required for follow up and for medicolegal aspects also. Dose of the drug was not written in 780/1428 of the drugs $(54.62 \%)$. Dose of the drug is needed for the Pharmacist while dispensing the drug to the patient. Drugs name in capitals was written in only $90 / 1428$ drugs $(6.3 \%)$. Duration of treatment was not written in $5 \%$ of the total drugs prescribed. Duration of treatment is required by pharmacist while dispensing the drug.

It is necessary to motivate the physicians to write doctors details like doctor's sign, which carries medicolegal significance. Also writing patient details like patient age, sex and address are of utmost importance as it is needed for follow up and it also carries medicolegal significance. Dose of the drug and duration of therapy was also missing in many prescriptions which are required by the pharmacist while dispensing the drug to the patient.

\section{CONCLUSION}

There is an ample scope of improving the prescribing pattern by keeping the number of medicines as low as possible, prescribing medicines by generic names, using medicines appropriately after selecting and consciously keeping the cost of therapy low. Doctors details and patient details are of utmost importance while prescribing. Physicians should be aware of dose of drug and duration of therapy while prescribing so that the pharmacist can easily dispense the drugs.

Also, dose of drug and duration of therapy carry medicolegal significance. From above finding and results it can be concluded that such type of study will help in promoting, to design policy and motivation of physician for rational use of drugs.

\section{ACKNOWLEDGEMENTS}

The authors are grateful to the staff of General Medicine department ARMCH, Kumbhari for providing facilities to carry out this project successfully.

Funding: No funding sources Conflict of interest: None declared

Ethical approval: The study was approved by the Institutional Ethics Committee

\section{REFERENCES}

1. Tiwari H, Kumar A, Kulkarni SK. Prescription monitoring of antihypertensive drug utilisation at the Panjab University Health Centre in India. Singapore Med J. 2004;45(3):117-20.

2. World Health Organization (WHO). WHO Expert Committee on The Selection of Essential Drugs. The Selection of Essential Drugs: first report of the WHO Expert Committee. 1977.

3. Sacristán, JA, Soto J. Drug Utilisation Studies as Tools in Health Economics. Pharmacoeconomics. 1994; 5(4):299-312.

4. Kulkarni MD, Baig MS, Hussaini SA, Doifode SM. Drug utilization pattern in OPD of government dental college and hospital, Aurangabad. Int J Basic Clinc Pharmacol. 2013;2:69-70.

5. Abidi A, Gupta S, Kansal S, Ramgopal. Prescription auditing and drug utilization pattern in a tertiary care teaching hospital of western UP. Int J Basic \& Clin Pharmacol. 2012;1(3):184-90.

6. Chandra S, Khan IN, Mateenudin M, Chandrakapure A, Maaz S, Mubin F. Drug utilization study in OPD of a tertiary care hospital in a rural area of Jalna, Maharashtra, India by using WHO prescribing indicators. Int J Basic \& Clin Pharmacol. 2018;7(1): 55-8.

7. Bhosale RR, Ramanand JB , Ramanand SJ, Zende AM, Padwal SL, Jadhav RR. Drug utilization pattern in outpatient department of Government Medical College and C.P.R. Hospital, Kolhapur. International J Basic \& Clin Pharmacol. 2013;2(4):403-6.

8. Gama H. Drug Utilization Studies. Arquivos de Medicina. 2008;22(2/3):69-74.

9. JR Laporte, M Porta, D Capella. Drug utilization studies: a tool for determining the effectiveness of drug use. British J Clinical Pharmacol. 1983;16:3014.

10. Ajapuje P, Dhengre P, Giri VC, Khakse GM. Drug Prescription Practices among Pediatric Patients in Yavatmal, Central India. Int $\mathrm{J}$ Recent Trends in Science and Technol, ISSN 2277-2812 E-ISSN 22498109. 2012;5(2):104-6.

11. Bajait CS, Pimpalkhute SA, Sontakke SD, Jaiswal KM, Dawri AV. Prescribing pattern of medicine in chronic kidney disease with special emphasis on phosphate binders. I J Pharmacol. 2014Jan:46:35-9.

12. Appendix -1. List of Essential medicine. In: Tripathi KD $7^{\text {th }}$ Ed. Jaypee Brothers. Reprint; 2014:957-61.

Cite this article as: Bhalerao PP, Waghmare CS.

Drug utilisation study in medicine outpatient department at ashwini rural medical college, kumbhari, solapur. Int J Basic Clin Pharmacol 2019;8:1919-22. 